\title{
Performance Assessment and Parametric Design of a Combined System Consisting of High-Temperature Proton Exchange Membrane Fuel Cell and Absorption Refrigerator
}

\author{
Yuan Han ${ }^{1}$, Xinru Guo ${ }^{1}$, Houcheng Zhang, ${ }^{1, *}$ Ziyang Hu${ }^{1}$, Shujin Hou ${ }^{2, *}$ \\ ${ }^{1}$ Department of Microelectronic Science and Engineering, Ningbo University, Ningbo 315211, China \\ ${ }^{2}$ College of Physics and Electronic Engineering, Nanyang Normal University, Nanyang 473061, \\ China \\ *E-mail: zhanghoucheng@ @bu.edu.cn (H. Zhang); houshujingrb@163.com (S. Hou).
}

doi: $10.20964 / 2019.09 .33$

Received: 20 April 2019 / Accepted: 30 June 2019 / Published: 31 July 2019

\begin{abstract}
A theoretical model of a combined system composed of a high-temperature proton exchange membrane fuel cell (HT-PEMFC), a regenerator and an absorption refrigerator (APR) is established, where the APR is used to absorber the waste heat from HT-PEMFC for cooling production. By taking irreversible losses within the proposed system into account, mathematical expressions of the equivalent output power and efficiency for HT-PEMFC, APR and the combined system are derived and the optimum operating regions of system performance parameters are obtained. In addition, the effects of key parameters such as operating temperature, doping level, relative humidity, proton exchange membrane thickness and some composite parameters on the combined system performance are discussed in detail. The obtained results can provide some guidelines for the integration and design of such an actual system.
\end{abstract}

Keywords: High-temperature proton exchange membrane fuel cell; Absorption Refrigerator; Waste heat recovery; Performance analysis; Parametric design

\section{FULL TEXT}

(C) 2019 The Authors. Published by ESG (www.electrochemsci.org). This article is an open access article distributed under the terms and conditions of the Creative Commons Attribution license (http://creativecommons.org/licenses/by/4.0/). 